\title{
Magnet Thermal and Magnetization State Monitoring in PMSMs Based on Magnet Resistivity Estimation
}

\author{
Daniel Fernández, David Reigosa, A. B. Diez, J. M. Guerrero and Fernando Briz \\ "University of Oviedo. Dept. of Elect., Computer \& System Engineering, Gijón, 33204, Spain. \\ fernandezalodaniel@uniovi.es, diazdavid@uniovi.es, abdiez@uniovi.es, guerrero@uniovi.es, fernando@isa.uniovi.es
}

\begin{abstract}
Thermal and magnetization state monitoring of permanent magnet synchronous machines (PMSMs) is important for control and reliability issues. Magnet resistance can be used for this purpose as it directly depends on PM temperature and magnetization state. Injection of a high frequency (HF) signal in the stator via inverter has been demonstrated to be a viable option for magnet resistance estimation as it does not interfere with the normal operation of the drive and can be implemented therefore in real time. Furthermore, this method can be applied to both interior PMSMs (IPMSMs) and surface PMSMs (SPMSMs). This paper reviews the use of magnet resistance for thermal and magnetization state monitoring of PMSMs, with special focus on the expected accuracy and sensitivity to operating condition of the machine. ${ }^{1}$
\end{abstract}

Index Terms - High frequency signal injection, permanent magnet synchronous machines, temperature estimation, magnetization state estimation.

\section{Introduction}

PMSMs have sustainably gained importance over the last three decades due to their high dynamic performance, power density and efficiency. Torque production capability of PMSMs depends on the magnetization state of the PMs [1]. PM magnetization state can change during the normal operation of the machine due to fundamental current injection [2]-[3] and temperature variations [1], [8]-[15]. Methods for the monitoring of PMs thermal [8]-[15] and/or magnetization state have been therefore extensively studied for control and reliability purposes [24]-[29].

Thermal overloading can severely affect to the performance of electric drives and is a major source of motor failures. The consequences of excessive temperatures will depend on the type of machine. For the case of induction machines and synchronous reluctance machines, the design of the rotor is very robust; degradation of the stator windings insulation due to excessive temperatures being a major concern in this case [4]-[6]. On the contrary, for the case of PMSMs, the temperature dependency of PMs shifts the concerns to the rotor side [7]-[15]. High temperatures of the magnets result in a decrease of the magnet strength, reducing therefore the torque production capability. Furthermore, excessive temperature of the magnets can produce an

\footnotetext{
${ }^{1}$ This work was supported in part by the Spanish Ministry of Economy and Competitiveness under grant MINECO-17-ENE2016-80047-R. D. Reigosa, D. Fernández, A. B. Diez, J. M. Guerrero and F. Briz are with the Department of Electrical, Computer \& System Engineering, University of Oviedo, Campus de Gijón, 33204, Gijón, Spain.
}

978-1-5386-4455-3/18/\$31.00 @2018 IEEE irreversible demagnetization. Consequently thermal monitoring of the machine in electric drives is of great importance in many applications both for reliability and control reasons.

Machine temperature can be measured or estimated. Measurement of the stator temperature is relatively easy and is often implemented in standard machines [4]-[6], [8]-[11], [12], [13], [16]. Measurement of the rotor temperature is significantly more difficult. Contact sensors require cabling to a rotating part, or some type of wireless transmission, both options being problematic [10]-[11]. Non-contact sensors (e.g. infrared) can be used [10] but they also imply price and reliability concerns.

Alternatively to direct PM temperature measurement, it can be estimated. PM temperature estimation methods can be divided into thermal models [17]-[18], BEMF based methods [19]-[20] and methods that inject some form of test signal into the stator terminals of the machine [9], [10]-[11], [14], [15]. Thermal based methods require precise knowledge of the geometry and cooling system of the machine, as well as of the environmental conditions [17][18], requiring therefore a careful adjustment for each machine and application. BEMF methods cannot work at standstill or very low speeds [19]-[20], and require precise $d$ and $q$-axis inductance maps [19]-[20]. Signal injection methods can be further divided into pulse injection [9], [14], [15], and high frequency (HF) signal injection methods [10][11]. Pulse injection methods rely on the dependency of the stator $d$-axis inductance on the magnet magnetization state, which is a function of magnet temperature [9], [14]. HF signal injection methods rely on the dependency of the stator $\mathrm{HF}$ resistance on the magnet resistance [10]-[11], which is also a function of magnet temperature [10]-[11]. These methods do not require previous knowledge of the machine geometry or cooling system, they do not need additional sensors (and cabling) either; still the need to inject an additional signal will have adverse effects with must be considered.

In addition to PM temperature, knowledge its magnetization state can be also highly relevant for monitoring and control purposes. Measuring the magnetization state once the machine is assembled is not easy. This can be done by inserting a gauss meter in the machine air gap [21]-[22]. However this requires removing or drilling the end frame of the machine to insert the field sensor, being only feasible with the machine at standstill. Use of field sensors inserted between PMs and rotor lamination combined with a wireless transmission was 


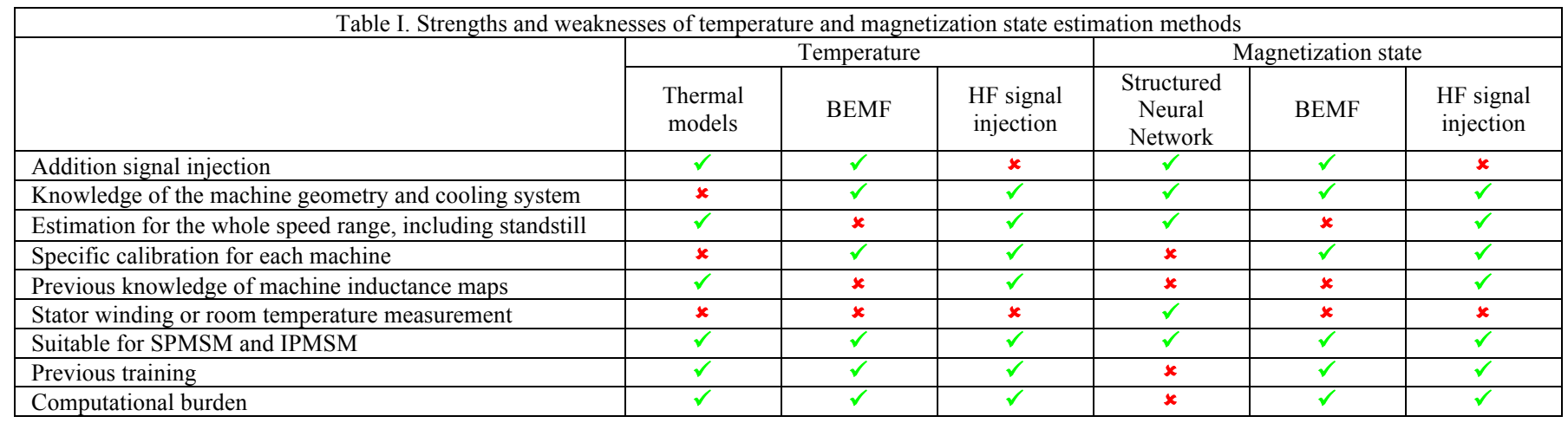

proposed in [23]. While real time measurement of the magnetization state and without interfering with the normal operation of the machine is possible, its cost is unacceptable for commercial applications, also compromises the robustness of the drive.

Alternatively to direct measurement, PM magnetization state can be estimated, use of the BEMF [24]-[26], HF signal injection [27]-[28] and structured neural networks (SNN) [29] have been reported in the literature. SNN methods require a previous training process of the neural network, requiring therefore a careful adjustment for each machine; the computational burden could be also a critical issue. Previous discussion on BEMF and HF signal injection methods for temperature estimation also applies in this case, HF signal injection based methods relying now on the magnetoresistance effect [27]-[28]. Table I summarizes the strengths and weaknesses of temperature and magnetization state estimation methods.

The main purpose of this paper is to discuss the potential of $\mathrm{HF}$ signal injection methods for temperature and magnetization state estimation of PMSM drives, starting from their physical principles of operation. Extensive experimental results will be provided.

\section{HF model of a PMSM}

This section briefly describes the HF model of a PMSM. The general model of a PMSM in a reference frame synchronous with the rotor is given by (1) where $R_{d}, R_{q}, L_{d}$ and $L_{q}$ are the $d$ and $q$-axes resistances and inductances respectively and $\lambda_{p m}$ is the PM flux.

$$
\begin{aligned}
{\left[\begin{array}{c}
v_{s d}^{r} \\
v_{s q}^{r}
\end{array}\right]=} & {\left[\begin{array}{cc}
R_{d} & 0 \\
0 & R_{q}
\end{array}\right]\left[\begin{array}{c}
i_{s d}^{r} \\
i_{s q}^{r}
\end{array}\right]+} \\
& p\left[\begin{array}{cc}
L_{d} & 0 \\
0 & L_{q}
\end{array}\right]\left[\begin{array}{c}
i_{s d}^{r} \\
i_{s q}^{r}
\end{array}\right]+ \\
& {\left[\begin{array}{cc}
0 & -\omega_{r} L_{q} \\
\omega_{r} L_{d} & 0
\end{array}\right]\left[\begin{array}{c}
i_{s d}^{r} \\
i_{s q}^{r}
\end{array}\right]+\left[\begin{array}{c}
0 \\
\lambda_{p m} \omega_{r}
\end{array}\right] }
\end{aligned}
$$

If the stator is fed with a HF voltage/current, the magnet flux dependent term in (1) can be safely neglected, as it does not contain any HF component, the resulting HF model being (2).

$$
\begin{aligned}
{\left[\begin{array}{c}
v_{s d H F}^{r} \\
v_{s q H F}^{r}
\end{array}\right]=} & {\left[\begin{array}{cc}
R_{d H F} & 0 \\
0 & R_{q H F}
\end{array}\right]\left[\begin{array}{l}
i_{s d H F}^{r} \\
i_{s q H F}^{r}
\end{array}\right]+} \\
& p\left[\begin{array}{cc}
L_{d H F} & 0 \\
0 & L_{q H F}
\end{array}\right]\left[\begin{array}{l}
i_{s d H F}^{r} \\
i_{s q H F}^{r}
\end{array}\right]+ \\
& {\left[\begin{array}{cc}
0 & -\omega_{r} L_{q H F} \\
\omega_{r} L_{d H F} & 0
\end{array}\right]\left[\begin{array}{l}
i_{s d H F}^{r} \\
i_{s q H F}^{r}
\end{array}\right] }
\end{aligned}
$$

If the frequency of the injected HF signal is sufficiently higher than the rotor frequency, the rotor speed dependent terms can also be safely neglected, the simplified HF model shown in (3) being obtained. An indicative threshold for this assumption can be $\omega_{h f}>\omega_{r}+2 \cdot \pi \cdot 500[11]$.

$$
\begin{aligned}
{\left[\begin{array}{c}
v_{s d H F}^{r} \\
v_{s q H F}^{r}
\end{array}\right]=} & {\left[\begin{array}{cc}
R_{d H F} & 0 \\
0 & R_{q H F}
\end{array}\right]\left[\begin{array}{c}
i_{s d H F}^{r} \\
i_{s q H F}^{r}
\end{array}\right]+} \\
& p\left[\begin{array}{cc}
L_{d H F} & 0 \\
0 & L_{q H F}
\end{array}\right]\left[\begin{array}{c}
i_{s d H F}^{r} \\
i_{s q H F}^{r}
\end{array}\right]
\end{aligned}
$$

\section{Magnet temperature and magnetization state estimation using a HF signal}

The physical principles for PM temperature and magnetization state estimation in PMSMs using HF signal injection can be deduced from (2)-(3). The behavior of the stator and rotor $\mathrm{HF}$ resistances with temperatures are given by (4)-(6) where $T_{s}, T_{r}$ and $T_{0}$ are the stator, rotor and room temperatures, $B_{r}$ is the PM flux, $B_{r 0}$ is the rated PM flux (i.e. at room temperature and when no $d$-axis fundamental current is injected); $R_{s H F\left(T_{0}\right)}, R_{d r H F\left(T_{0}, B_{r 0}\right)}$ and $R_{q r H F\left(T_{0}\right)}$ are the stator, rotor $d$-axis and rotor $q$-axis $\mathrm{HF}^{r}$ resistance at the room temperature and rated PM flux; $\alpha_{c u}, \alpha_{d_{-} m a g}, \alpha_{q_{-} m a g}$ account for the copper, $d$ and $q$-axis magnet thermal resistive coefficients [10]-[11] respectively and $\beta$ accounts for the magnet magnetoresistive coefficient [27]-[27].

$$
\begin{aligned}
& R_{s H F\left(T_{s}\right)}=R_{s H F\left(T_{0}\right)}\left(1+\alpha_{c u}\left(T_{s}-T_{0}\right)\right) \\
& R_{d r H F\left(T_{r}, B_{r}\right)}=R_{d r H F\left(T_{0}, B_{r 0}\right)}\left(1+\alpha_{d_{-} m a g}\left(T_{r}-T_{0}\right)+\beta\left(B_{r}-B_{r 0}\right)\right) \\
& R_{q r H F\left(T_{r}\right)}=R_{q r H F\left(T_{0}\right)}\left(1+\alpha_{q_{-} \text {mag }}\left(T_{r}-T_{0}\right)\right)
\end{aligned}
$$


The $d$ and q-axis components of the overall HF resistances seen from the stator terminals $R_{d H F}$ and $R_{q H F}$ (7)-(8), are seen to be a function of both the stator and rotor HF resistances, where $R_{s H F}$ is the contribution of the stator circuit to the HF resistance and $R_{d r H F}$ and $R_{q r H F}$ are the stator-reflected $d$ and $q$-axes components of the rotor HF resistance.

$$
\begin{aligned}
& R_{d H F\left(T_{s}, T_{r}, B_{r}\right)}=R_{s H F\left(T_{s}\right)}+R_{d r H F\left(T_{r}, B_{r}\right)} \\
& R_{q H F\left(T_{s}, T_{r}\right)}=R_{s H F\left(T_{s}\right)}+R_{q r H F\left(T_{r}\right)}
\end{aligned}
$$

It is seen from (4)-(6) and (7)-(8) that the magnet temperature, $T_{r}$, and magnetization state, $B_{r}$, can be estimated from the overall $d$-axis HF resistance. Knowledge of the HF resistance of the machine at the room temperature and of the stator temperature is required. The HF resistance of the machine at the room temperature can be measured during a commissioning process. The stator temperature can be easily measured via a contact type temperature sensor (e.g. thermocouple). It is noted that both the temperature and field induce a variation of the magnet resistance. To the best of authors' knowledge, no method has been proposed to separate the contribution of these two effects on the overall magnet HF resistance. This is therefore a topic of tremendous interest..

Estimation of the $d$-axis HF resistance (7) can be done by injecting a high frequency signal into the stator terminals of the machine. Use of rotating high frequency voltage injection; pulsating $d$-axis high frequency current; and pulsating $d$-axis voltage with $q$-axis current cancellation have been reported in the literature [10]-[11], the last two options showing superior performance [11]. Pulsating $d$-axis high frequency current is discussed next;.

Magnet $H F$ resistance estimation using $d$-axis pulsating current injection

This method uses a resonant controller to inject a HF current that has to be injected in the $d$-axis (9), i.e. aligned with the PMs. The HF voltages commanded by the resonant controller are (10). By taking only the $d$-axis component of the resulting HF voltage complex vector, $v_{d q s H F}^{r * *}$ in (10), the voltage complex vector $v_{d q s H F}^{r^{\prime}},(11)$, is defined. Both (9) and (11) can be separated into positive sequence $\left(i_{d q s H F p c}^{r^{*}}\right.$ and $\left.v_{d q s H F p c}^{r^{\prime}}\right)$ and negative sequence ( $i_{d q s H F n c}^{r *}$ and $\left.v_{d q s H F n c}^{r}\right)$ components, (12) and (13), each with a magnitude equal to half of that of the original signal. The $d$-axis HF impedance, (14), can be obtained either from the positive or negative sequence components. The $d$-axis HF resistance is finally obtained as the real part of $d$-axis HF impedance, (15).

$$
\begin{aligned}
& i_{d q s H F}^{r^{*}}=\left[\begin{array}{c}
\bar{I}_{d H F}^{r^{*}} \\
\bar{I}_{q H F}^{r^{*}}
\end{array}\right]=\left[\begin{array}{c}
I_{H F}^{*} \cos \left(\omega_{H F} t\right) \\
0
\end{array}\right] \\
& v_{d q s H F}^{r^{*}}=\left[\begin{array}{c}
\bar{V}_{d s H F}^{r^{*}} \\
\bar{V}_{q s H F}^{r^{*}}
\end{array}\right]=\left[\begin{array}{c}
\left(R_{d H F}+j \omega_{H F} L_{d H F}\right) \bar{I}_{d H F}^{r} \\
\omega_{r} L_{d H F} \bar{I}_{d H F}^{r}
\end{array}\right]
\end{aligned}
$$

$$
\begin{aligned}
v_{d q s H F}^{r^{\prime}}=\left[\begin{array}{c}
\bar{V}_{d s H F}^{r^{*}} \\
0
\end{array}\right]=\left[\begin{array}{c}
\left(R_{d H F}+j \omega_{H F} L_{d H F}\right) \bar{I}_{d H F}^{r^{*}} \\
0
\end{array}\right]= \\
{\left[\begin{array}{c}
\left.V_{d q s H F}^{r^{\prime}} \cos \left(\omega_{H F} t+\varphi_{Z d}\right)\right] \\
0
\end{array}\right]=} \\
i_{d q s H F}^{r^{*}}=\frac{I_{H F}^{*}}{2} e^{j \omega_{H F} t}+\frac{I_{H F}^{*}}{2} e^{-j \omega_{H F} t}=i_{d q s H F p c}^{r^{*}}+i_{d q s H F n c}^{r^{*}} \\
v_{d q s H F}^{r^{\prime}}=\frac{\left|v_{d q s H F}^{r^{\prime}}\right|}{2} e^{j\left(\omega_{H F} t-\varphi_{Z d}\right)}+\frac{\left|v_{d q s H F}^{r^{\prime}}\right|}{2} e^{j\left(-\omega_{H F} t^{\left.t+\varphi_{Z d}\right)}\right.}= \\
v_{d q s H F p c}^{r^{\prime}}+v_{d q s H F n c}^{r^{\prime}}=R_{d H F}+j \omega_{H F} L_{d H F}=\frac{v_{d q s H F p c}^{r^{\prime}}}{i_{d q s H F p c}^{r^{*}}}=\frac{v_{d q s H F n c}^{r^{\prime}}}{i_{d q s H F n c}^{r^{*}}} \\
R_{d H F F}=\Re\left[Z_{d H F}\right]
\end{aligned}
$$

Combining (4), (5) and (7), the rotor $d$-axis HF resistance $R_{d H F}$ can be written as (16), from which the magnet temperature is obtained using (17).

$$
\begin{gathered}
R_{d H F\left(T_{s}, T_{r}, B_{r}\right)}=R_{d s H F\left(T_{0}\right)}\left(1+\alpha_{c u}\left(T_{s}-T_{0}\right)\right)+ \\
R_{d r H F\left(T_{0}, B_{r 0}\right)}\left(1+\alpha_{\text {mag }}\left(T_{r}-T_{0}\right)+\beta\left(B_{r}-B_{r 0}\right)\right) \\
T_{r}=\frac{R_{d H F\left(T_{s}, T_{r}, B_{r}\right)}-R_{d s H F\left(T_{0}\right)}\left(1+\alpha_{c u}\left(T_{s}-T_{0}\right)\right)}{R_{d r H F\left(T_{0}, B_{r 0}\right)} \alpha_{m a g}}- \\
\frac{R_{d r H F\left(T_{0}, B_{r 0}\right)}\left[1-\alpha_{\text {mag }} T_{0}+\beta\left(B_{r}-B_{r 0}\right)\right]}{R_{d r H F\left(T_{0}, B_{r 0}\right)} \alpha_{\text {mag }}}
\end{gathered}
$$

The PM magnetization state can be obtained form (16) as (18).

$$
\begin{gathered}
B_{r}=\frac{R_{d H F\left(T_{s}, T_{r}, B_{r}\right)}-R_{d s H F\left(T_{0}\right)}\left(1+\alpha_{c u}\left(T_{s}-T_{0}\right)\right)}{R_{d r H F\left(T_{0}, B_{r 0}\right)} \beta}- \\
\frac{R_{d r H F\left(T_{0}, B_{r 0}\right)}\left[1-\beta B_{r 0}+\alpha_{\text {mag }}\left(T_{r}-T_{0}\right)\right]}{R_{d r H F\left(T_{0}, B_{r 0}\right)} \beta}
\end{gathered}
$$

\section{Experimental results}

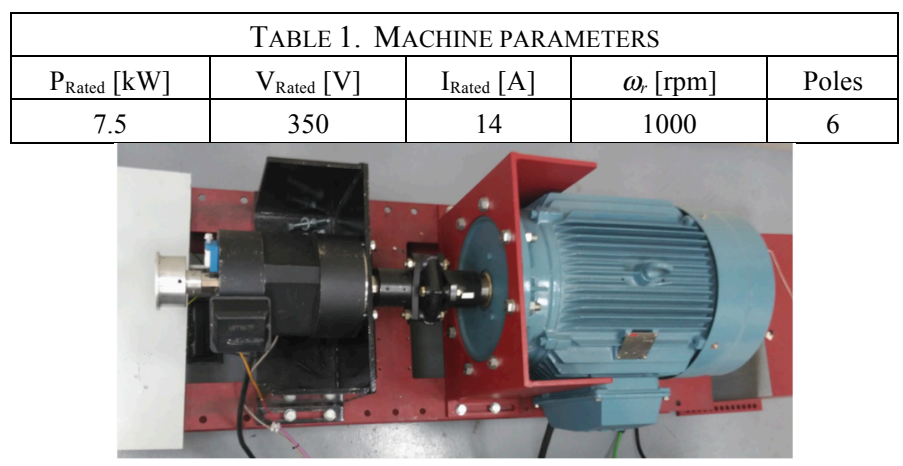

Fig. 1.- Test bench. 
a)
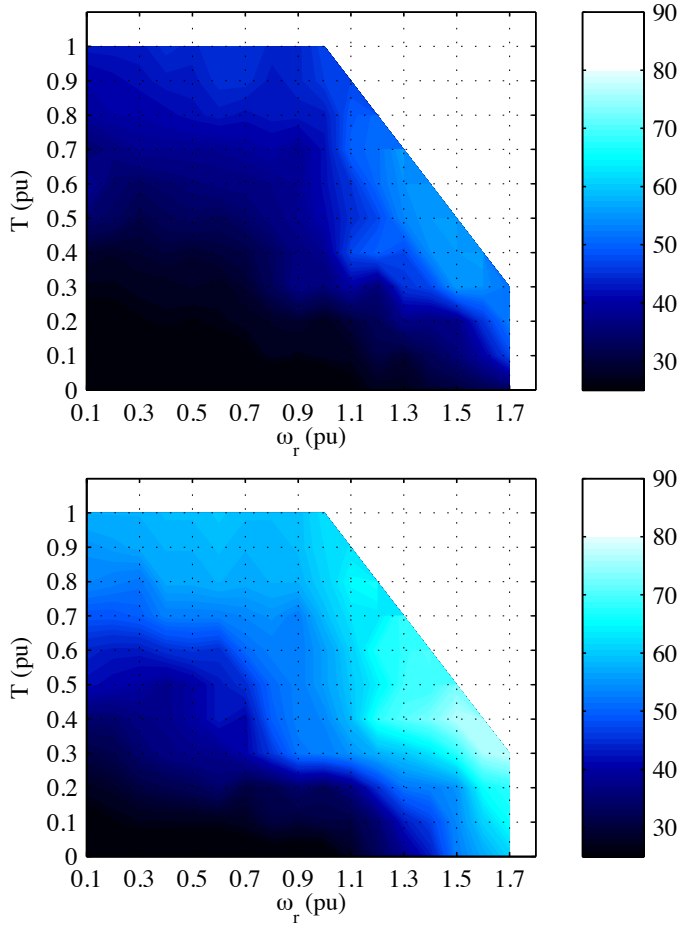

b)

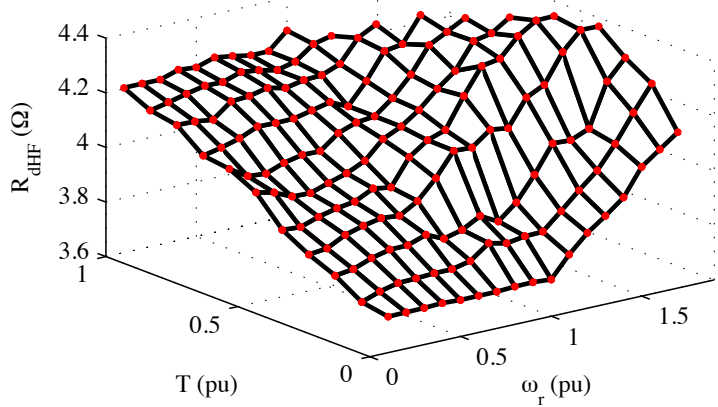

c)

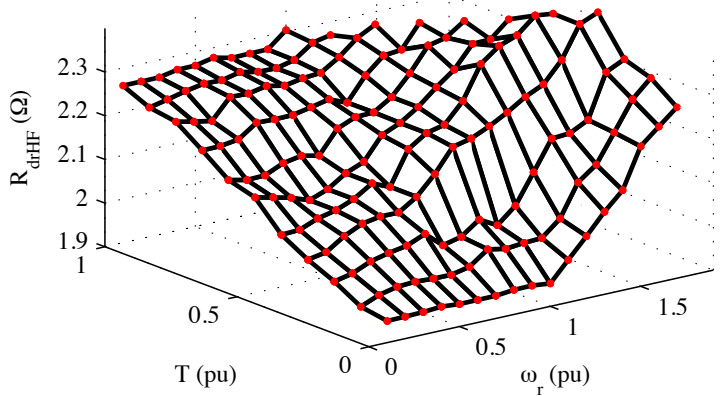

$\left({ }^{\circ} \mathrm{C}\right)$

e)
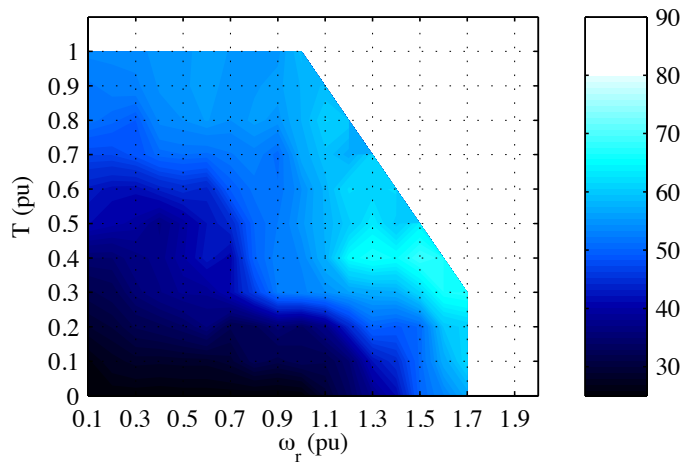

$\left({ }^{\circ} \mathrm{C}\right)$

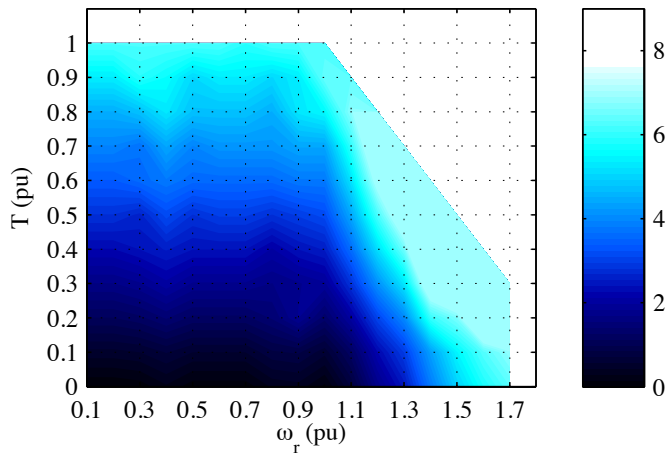

$\left({ }^{\circ} \mathrm{C}\right)$

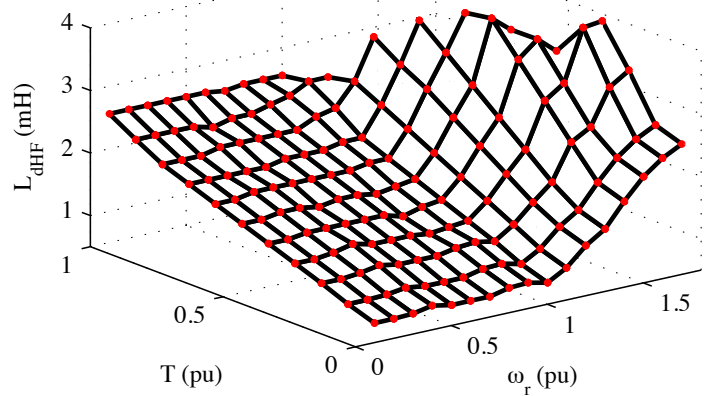

g)

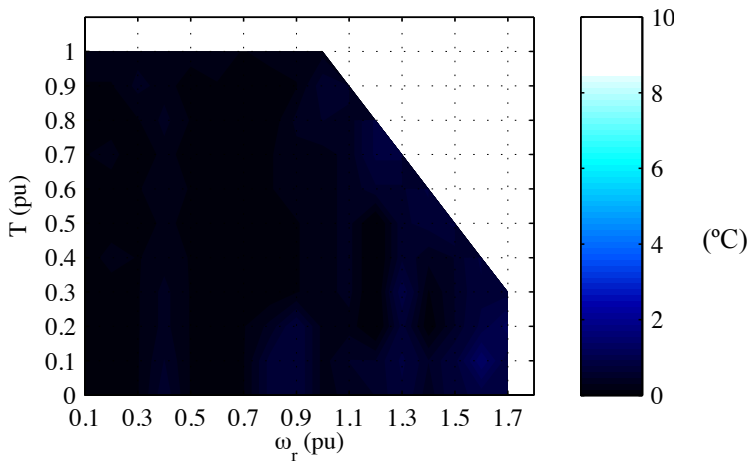

h)

Fig. 2.- Temperature estimation using HF signal injection. (a) Measured stator temperature. (b) Measured rotor temperature. (c) Estimated stator high frequency resistance, $R_{d H F}(7)$. (d) Estimated stator-reflected magnet high frequency resistance, $R_{d r H F}(5)$. (e) Estimated magnet temperature. (f) Magnet temperature estimation error. (g) $d$-axis high frequency inductance. (h) Magnet temperature estimation error after decupling the magnetoresistive effect. $\omega_{\mathrm{hf}}=2 \cdot \pi \cdot 250 \mathrm{rad} / \mathrm{s}$ and $I_{\mathrm{hf}}=0.05$ p.u..

Experimental results showing the performance of temperature and magnetization state estimation in an IPMSM are shown in this section. Machine's parameters are given in Table 1; Fig. 1 showing the test bench.

\section{A) Temperature estimation}

Fig. 2 shows experimental results showing the performance of temperature estimation in the test machine. Data was collected with both torque and speed being varied from zero to their corresponding rated value in steps of $0.1 \mathrm{pu}$. The stator temperature was measured using a contact type thermometer (PT-100) and further compensated. To assess the accuracy of the method, the magnet temperature was obtained as the average of the measurement provided by the system described in [23]. MTPA is not implemented, (i.e. $I_{d}=0$ for $\omega_{r}<1 \mathrm{pu}$ and 
$I_{d} \neq 0$ for $\left.\omega_{r}>1 \mathrm{pu}\right)$. This allows analyzing the effects of changes in $I_{q}, I_{d}$ and $\omega_{r}$ separately.

It is observed from Fig. 2 that both the stator, a), and rotor temperatures, b), increase with the load due to the copper, eddy current and hysteresis losses, this was an expected result [10]-[11]. The machine temperature also increases with the speed, due to the increased eddy currents and hysteresis losses with frequency. The most critical working conditions (higher temperatures) occur therefore in the flux-weakening region. Fig. 2c shows the estimated $d$-axis high frequency resistance $\left(R_{d H F}(7)\right)$, and Fig. $2 \mathrm{~d}$ shows the stator reflected rotor high frequency resistance $\left(R_{d r H F}(5)\right),\left(\alpha_{\text {mag }} \approx 0.0023 /{ }^{\circ} \mathrm{C}\right)$. $\quad$ Fig. $2 \mathrm{e}$ shows the estimated magnet temperature using (17) while Fig. 2f shows the estimated magnet temperature error; speed and load $\left(I_{q}\right)$ are seen to have negligible impact on the temperature estimation error. It is interesting to note the increased error in the estimated temperature in the field-weakening region $\left(I_{d}\right)$. This behavior is due to the magnetoresistive effect, since the injection of $d$-axis current changes the magnetization state of the machine. Fig. $2 \mathrm{~g}$ shows the $d$-axis high frequency inductance, which can be easily obtained from the induced $q$ axis high frequency voltage when injecting a pulsating $d$-axis high frequency current (10). The $d$-axis high frequency inductance is a reliable metric of the magnetoresistive effect, i.e. of the magnetization state of the machine, meaning that it can be used to compensate for the magnetoresistive effect in the estimated magnet temperature. Fig. $2 \mathrm{~h}$ shows the error in the estimated magnet temperature after decoupling the magnetoresistive effect, the error being limited to $\approx 2^{\circ} \mathrm{C}$.

\section{B) Magnetization State estimation}

Fig. 3 shows the estimated $d$-axis stator-reflected magnet $\mathrm{HF}$ resistance and magnetization state estimation error vs. the magnetization state and speed for the test machine (see Table 1). Magnetization state was varied between the maximum $(1.28 \mathrm{~T}$ for $\mathrm{N} 32 \mathrm{SH})$ and minimum permissible limits, $\approx 0.804 \mathrm{~T}$. To assess the accuracy of the method, the magnet magnetization state was obtained as the average of the measurement provided by the system described in [23]. For each magnetization state condition, the speed was varied in steps of $0.1 \mathrm{pu}$ from zero up to the maximum permissible speed. It is observed that the speed has a negligible impact on the estimated $d$-axis stator-reflected magnet HF resistance and consequently on the magnetization state estimation error. The method provides therefore similar performance in the whole speed, including standstill. The magnetization state estimation error is observed to slightly increase with the magnetization level. This is due to the reduction of the sensitivity of the estimated HF resistance variation with the PM magnetization for high magnetization states [27]-[27]. The maximum magnetization state estimation error is $\approx 0.052 \mathrm{~T}$.

\section{Conclusions}

This paper reviews the use of magnet resistance for thermal and magnetization state monitoring in PMSM drives. Injection of a HF signal via inverter superposed on top of the

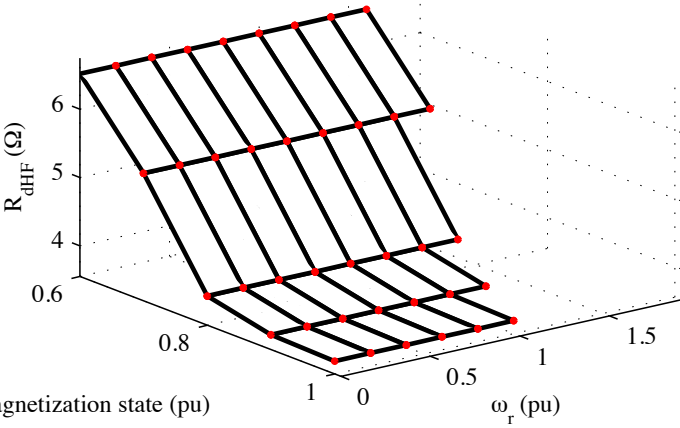

a) ${ }^{\mathrm{Mag}}$

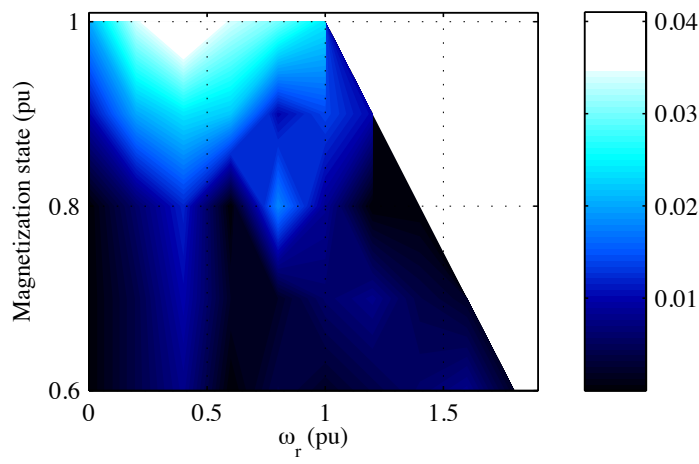

(pu)

Fig. 3.- Magnetization state estimation. (a) Estimated $d$-axis stator-reflected magnet resistance. (b) Magnetization state estimation error vs. magnetization state $\&$ speed. $\omega_{\mathrm{hf}}=2 \cdot \pi \cdot 250 \mathrm{rad} / \mathrm{s}$ and $I_{\mathrm{hf}}=0.05$ p.u..

fundamental excitation is used for this purpose. The method does not require to discontinue the normal operation of the machine, can be used in the whole working range (speed and torque), and has a reduced impact on the performance of the machine (losses, vibration, ...). While magnet temperature and magnetization state estimation has been shown to be feasible separately, simultaneous estimation of both is perhaps the major challenge for these methods. Experimental results using pulsating $d$-axis HF current injection have been provided to demonstrate the feasibility of the method.

\section{References}

[1] J. F. Gieras and M. Wing, "Permanent magnet motor technology: design and application". Second edition 2002.

[2] N. Limsuwan, T. Kato, K. Akatsu, and R. D. Lorenz, "Design and evaluation of a variable-flux flux-intensifying interior permanent-magnet machine," IEEE Trans. Ind. Appl., 50(2): 1015-1024, Mar./Apr. 2014.

[3] Athavale, K. Sasaki, B. S. Gagas, T. Kato, and R. D. Lorenz, "Variable Flux Permanent Magnet Synchronous Machine (VF-PMSM) Design Methodologies to Meet Electric Vehicle Traction Requirements with Reduced Losses," IEEE Trans. Ind. Appl., 53(5): 4318-4326, Sep./Oct. 2016.

[4] S. B. Lee and T. G. Habetler, "An online stator winding resistance estimation technique for temperature monitoring of line-connected induction machines," IEEE Trans. Ind. Appl., vol. 39, no. 3, pp. 684-685, May 2003.

[5] F. Briz, M. W. Degner, J. M. Guerrero and A. B. Diez, "Temperature Estimation in Inverter-Fed Machines Using High-Frequency Carrier Signal Injection," in IEEE Trans. on Ind. Appl., vol. 44, no. 3, pp. 799-808, Mayjune 2008 .

[6] J. Yang, J. Cho, S. B. Lee, J. Y. Yoo and H. D. Kim, "An Advanced Stator Winding Insulation Quality Assessment Technique for Inverter-Fed Machines," in IEEE Trans. on Ind. Appl., vol. 44, no. 2, pp. 555-564, Marchapril 2008 
[7] A. M. EL-Refai, N. C. Harris, T. M. Jahns,K. M. Rahman, "Thermal Analysis of Multibarrier Interior PM Synchronous Machine Using Lumped Parameter Model". IEEE Trans. on Energy Conv., 14(2):303-309, June 2004.

[8] C. Kral, A. Haumer and S. B. Lee, "A Practical Thermal Model for the Estimation of Permanent Magnet and Stator Winding Temperatures". IEEE Trans. on Pow. Elect., 29(1):455-464, Jan. 2014.

[9] M Ganchev, C. Kral and T. Wolbank, "Compensation of speed dependency in sensorless rotor temperature estimation for permanent-magnet synchronous motors," IEEE Trans. on Ind. Appl., 49(6): 2487-2495, Nov.Dec. 2013.

[10] D. D. Reigosa, F. Briz, P. Garcia, J. M. Guerrero and M. W. Degner, "Magnet Temperature Estimation in Surface PM Machines Using HighFrequency Signal Injection," in IEEE Trans. on Ind. Appl., vol. 46, no. 4, pp. 1468-1475, July-Aug. 2010.

[11] D. D. Reigosa, D. Fernandez, H. Yoshida, T. Kato and F. Briz, "PermanentMagnet Temperature Estimation in PMSMs Using Pulsating HighFrequency Current Injection," in IEEE Trans. on Ind. Appl., vol. 51, no. 4, pp. 3159-3168, July-Aug. 2015.

[12] B.-H. Lee, K.-S- Kim , J.-W. Jung, J.-P. Hong and Y.-K. Kim, “Temperature Estimation of IPMSM Using Thermal Equivalent Circuit ". IEEE Trans. on Mag., 48(4):2949-2952, Nov. 2012.

[13] A. J. Grobler, S. R. Holm and G. van Schoor, "Thermal Modeling of a High Speed Permanent Magnet Synchronous Machine". IEEE-IEMD, pp.319324, May 2013.

[14] M. Ganchev, C. Kral, and T. Wolbank, "Identification of sensorless rotor temperature estimation technique for permanent magnet synchronous motor," in Proc. Int. Symp. Power Electron., Electr. Drives, Autom. Motion, 2012, pp. 38-43.

[15] M Ganchev, C. Kral, H. Oberguggenberger and T. Wolbank, "Sensorless rotor temperature estimation of permanent magnet synchronous motor," IEEE IECON, pp. 2018-2023, Nov. 2011.

[16] S. D. Wilson, P. Stewart, and B. P. Taylor, "Methods of resistance estimation in permanent magnet synchronous motors for real-time thermal management," IEEE Trans. Energy Conver., vol. 25, no. 3, pp. 698-707, Sep. 2010.

[17] M. Kamiya, Y. Kawase, Y. Kosada and N. Matsui, "Temperature distribution analysis of permanent magnet in interior permanent magnet synchronous motor considering PWM carrier harmonics," IEEE-ICEMS, pp. 2023-2027, Oct. 2007.

[18] P. Milanfar and J. H.Lang, "Monitoring the thermal condition of permanentmagnet synchronous motors," IEEE Trans. on Aerospace and Electronic Systems, 32(4): 1421-1429, Oct. 1996.

[19] K. Liu and Z. Q. Zhu "Online Estimation of the Rotor Flux Linkage and Voltage-Source Inverter Nonlinearity in Permanent Magnet Synchronous Machine Drives," IEEE Trans. on Pow. Elect., 29(1): 418-427, Jan. 2014.

[20] [S. Ichikawa, M. Tomita, S. Doki, and S. Okuma, "Sensorless Control of Permanent-Magnet Synchronous Motors Using Online Parameter Identification based on System Identification Theory," IEEE Trans. Ind. Electron., 53(2): 363-372, Apr. 2006.

[21] J Hong, D Hyun, and S.B.Lee, "Automated monitoring of magnet synchronous motors at standstill," IEEE Trans. Ind. Appl., 46 (4): 1397 $1405,2010$.

[22] IEC 62. 2-2004., "IEEE guide for diagnostic field testing of electric power apparatus-electrical machinery," 2004.

[23] D. Fernandez, D. Reigosa, T. Tanimoto, T. Kato, and F. Briz, "Wireless permanent magnet temperature \& field distribution measurement system for IPMSMs," IEEE ECCE, pp. 3996-4003, Sep. 2015.

[24] X. Xiao, C. Chen and M. Zhang, "Dynamic Permanent Magnet Flux Estimation of Permanent Magnet Synchronous Machines", IEEE Trans. on Appl. Sup., 20(3): 1085-1088, June. 2010.

[25] K. Liu and Z. Q. Zhu "Online Estimation of the Rotor Flux Linkage and Voltage-Source Inverter Nonlinearity in Permanent Magnet Synchronous Machine Drives,” IEEE Trans. on Pow. Elect., 29(1): 418-427, Jan. 2014.

[26] K. Liu, Q. Zhang, J. Chen, Z. Q. Zhu, and J. Zhang, "Online multiparameter estimation of nonsalient-pole PM synchronous machines with temperature variation,” IEEE Trans. Ind. Electron., vol. 58, no. 5, pp. 1776-1788, May 2011.

[27] D. Reigosa, D. Fernandez, J. M. Guerrero, Z.Q. Zhu and F. Briz, "PMSM Magnetization State Estimation Based on Stator-reflected PM Resistance Using High Frequency Signal Injection", IEEE Trans. on Ind. Appl., 51(5): 3800-3810, Sept.-Oct. 2015.

[28] D. Fernandez, D. Reigosa, J. M. Guerrero, Z. Q. Zhu, C. Suarez and F. Briz, "Influence of PM Coating on PM Magnetization State Estimation Methods Based on Magnetoresistive Effect", IEEE Trans. on Ind. Appl., 54: accepted, publication pending, 2018. 10.1109/TIA.2018.2797883

[29] A. Athavale, K. Sasaki, T. Kato and R. D. Lorenz, "Magnetization State Estimation in Variable-Flux PMSMs," IEEE IEMDC, pp. 1-8, May 2017. 